This item was submitted to Loughborough's Research Repository by the author.

Items in Figshare are protected by copyright, with all rights reserved, unless otherwise indicated.

\title{
Why are we misdiagnosing urinary tract infection in older patients? A qualitative inquiry and roadmap for staff behaviour change in the emergency department
}

\section{PLEASE CITE THE PUBLISHED VERSION}

https://doi.org/10.1007/s41999-019-00191-3

\section{PUBLISHER}

Springer (c) European Geriatric Medicine Society

\section{VERSION}

AM (Accepted Manuscript)

\section{PUBLISHER STATEMENT}

This is a post-peer-review, pre-copyedit version of an article published in European Geriatric Medicine. The final authenticated version is available online at: https://doi.org/10.1007/s41999-019-00191-3.

\section{LICENCE}

CC BY-NC-ND 4.0

\section{REPOSITORY RECORD}

O'Kelly, Kate, Kay Phelps, Emma L. Regen, Fernando Carvalho, Desislava Kondova, Val Mitchell, Simon Conroy, and Gyuchan Thomas Jun. 2019. "Why Are We Misdiagnosing Urinary Tract Infection in Older Patients? A Qualitative Inquiry and Roadmap for Staff Behaviour Change in the Emergency Department". figshare. https://hdl.handle.net/2134/37635. 
Title: Why are we misdiagnosing Urinary Tract Infection in older patients? A qualitative inquiry and roadmap for staff behaviour change in the emergency department

Running title: UTI - to dip or not to dip?

Authors: Kate O’Kelly (kate_o_kelly@hotmail.com) ${ }^{1}$, BMBS; Kay Phelps (kp14@leicester.ac.uk)², BA; Emma L Regen (elr14@leicester.ac.uk)², MA; Fernando Carvalho (F.Carvalho@lboro.ac.uk) ${ }^{3}$, MFA; Desislava Kondova (Desislava.kondova@uhl-tr.nhs.uk) ${ }^{1}$, MB ChB; Val Mitchell (v.a.mitchell@lboro.ac.uk) ${ }^{3}$, PhD; Simon P Conroy (spc3@le.ac.uk)* , PhD; Gyuchan Thomas Jun (G.Jun@lboro.ac.uk)³, PhD.

1. Geriatric Medicine, University Hospitals of Leicester

2. Department of Health Sciences, University of Leicester

3. Loughborough Design School, Loughborough University

*Corresponding author: Simon P Conroy, Room 3.37, George Davies Centre, University of Leicester, University Road, Leicester, LE1 7RH. T: 00441162525992; E: spc3@le.ac.uk; Tw: @ GERED_ED. ORCID ID: 0000-0002-4306-6064

\section{Key points}

- The misdiagnosis of Urinary Tracy Infection (UTI), particularly in older people, is driven by complex, interconnected psychological and behavioural factors

- Factors include lack of knowledge on the role of urine dip testing, bias towards older people, automatic testing, time and resource constraints, pressures from peers and patients and legal pressures

- Developing interventions that address the disconnect between knowledge and practice by encompassing both psychological and behavioural factors may improve patient safety and staff satisfaction

- An improvement roadmap incorporating short, mid and long-term approaches can provide a structure for improvement efforts 


\section{Abstract (n=229 words)}

Purpose

The aim of this study was to identify the psychological and behavioural factors influencing clinicians managing older people with possible UTI in urgent care settings, and to develop an improvement roadmap.

\section{Methods}

Michie's behaviour change wheel and COM-B (Capability, Opportunity, Motivation - Behaviour change) models were used as the theoretical basis for this study. Semi-structured interviews were undertaken with twenty-one purposively selected medical and nursing staff in a large urban emergency department in the East Midlands, United Kingdom. Analysis was informed by the framework approach.

A participatory design approach was used to develop an improvement roadmap.

Results

Key themes emerging from the semi-structured interviews included lack of knowledge on the role of urine dipstick testing, bias towards older people, automatic testing, time and resource constraints, pressures from peers and patients, and fear of the legal consequences of inaction. A thematic networks map indicated complex interactions between psychological and behavioural factors. Among more than fifty different intervention ideas identified by the workshop participants, two interventions were prioritised for implementation: i) controlling the use of dip stick urine tests; ii) providing individualised feedback to staff regarding the outcomes of patients diagnosed and treated for UTI.

\section{Conclusions}

Psychological and behavioural factors play a significant role in the misdiagnosis of UTI in older people. Systematic approaches incorporating these factors might improve patient outcomes. Future studies should focus on implementation and evaluating their effectiveness and sustainability. 


\section{Key words}

- Older people

- Urinary tract infection

- Qualitative research

- Implementation

\section{Acknowledgements}

We are grateful to the staff (interviewees and stakeholders) who invested their time to discuss this issue, as well as to the follow colleagues who supported the project at various stages: Dr Natasha Lander, Dr Amelia Bull, Dr Kate Russ, Dr Emma Zain, Dr Muzamil Abbas, Dr Syed Babar

The project was funded by the British Geriatrics Society (BGS) via a Specialist Registrar Start-up Grant. Carvalho was funded by the Science without Borders programme (CNPq Brazil). The funders had no role in the study design, the conduct or the reporting.

The authors have no conflicts of interest to declare. 


\section{Background}

Urinary tract infection (UTI) is a very common clinical indication for antibiotic treatment, and the processing of urine samples is a major activity in microbiological laboratories $[1,2]$. There is general concordance in the literature concerning the definition of UTI - namely the importance of lower urinary tract symptoms and signs and the appropriate use of urinary dipstick testing (not recommended as the sole approach to diagnosis in older people) $[1,3,4]$. It is also well recognised that the diagnosis of UTI can be particularly difficult in older, frail or institutionalised patients in whom clinical presentations may well be atypical [5-10]. Furthermore, this group of patients have a high prevalence of asymptomatic bacteriuria, leading to positive urine dip tests, which can mislead clinicians $[11,12]$.

Despite existing guidance there is considerable variation in use of diagnostic tests, interpretation of signs and symptoms, and initiation of antibiotic treatment, with continued debate regarding the most appropriate diagnosis and treatment $[13,14]$. This variation is in part related to lack of awareness, a need to fulfil patient expectations, or a fear of adverse outcomes [15]. If these factors were better understood, then there would be the potential to design new approaches to improve the management of UTI in older people. More patients might be treated correctly and thus not be susceptible to the harms associated with misdiagnosis, including unnecessary antibiotics (leading to antimicrobial resistance) and Clostridium difficile [16-18].

Our theoretical stance was that the disconnect between what is known and what is practised could be described using psychological theory. We chose to use the Behaviour Change Wheel framework [19], which was devised by combining well known psychological theories and uses six categories (physical capability, psychological capability, physical opportunity, social opportunity, reflective motivation and automatic motivation) to explain gaps between knowledge and implementation.

The aim of this study was to describe the psychological and behavioural factors contributing to the incorrect diagnosis of urinary tract infection in older adults and identify potential interventions for improvement.

\section{Methods}

\section{Setting}

This study was undertaken in a large teaching hospital in the East Midlands, United Kingdom; it focussed on Emergency Department (ED) staff caring for older people with possible urinary tract infection. The department sees around 15,000 patients aged 65 or older each year, with key performance indicators frequently hovering 
around the average for the country as a whole (e.g. 4-hour emergency care standard). The pressures of emergency care (time pressures, competing priorities, high turnover of patients), are similar if not slightly greater in this department as for the rest of England.

This was a qualitative study, involving staff interviews, workshops, focus groups and on-going collaboration with relevant stakeholders [20]. The stakeholder group, which had representation from emergency and geriatric medicine, microbiology, pharmacy, urogynaecology and nursing, as well as design and healthcare social science research, advised on the study direction, methods, analysis and findings. An older people's Patient and Public Participation (PPI) forum was also consulted on study design, relevance, interpretation of findings and the implications for patients.

\section{Semi-structured interviews - analysis of contributing factors}

A semi-structured topic guide (see appendix) was developed after appraisal of the literature [15], and informed by the Behaviour Change Wheel [19]. Drafts of the topic guide were shared with the study stakeholder group and the PPI forum, modified in accordance with feedback received.

Front line clinical staff (totalling 180 nurses or Health Care Assistants (HCAs) and 100 doctors) were invited to participate, following authorisation and support from senior managers. Participants were identified purposively representing different roles and levels of seniority between January-March 2016. Recruitment continued until the desired range of staff had been included and no new themes were elicited. Written consent was gained from each participant prior to the interview commencing. In order to be minimally intrusive and respectful of clinicians' time, the research team remained flexible and 'on-hand' to conduct interviews at a time of the clinicians' choosing - for example to coincide with staff breaks or relatively quieter periods in ED. Interviews typically lasted 30-45 minutes and were audio-recorded and transcribed.

Interviews were analysed using the framework approach [21] and analysed in NVivo 10; emerging themes were used to generate a coding framework which was subsequently used to code the interview transcripts. In the interests of validity and reliability, themes generated during the analysis process were discussed and validated by members of the research team on a regular basis. Data collection and analysis were concurrent, with early findings directing further enquiries in interviews. Patterns, associations, concepts and explanations in the data were identified via a process of mapping and interpretation which drew upon the domain list and six components set out in the COM-B model of the Behaviour Change Wheel [19]: i) social opportunity; ii) physical opportunity; iii) psychology capability; iv) physical capability; v) reflective motivation; vi) automatic 
motivation. The main interpretations stemming from the data analysis were visually summarised in a thematic networks map whereby organising themes and basic themes were identified and placed around the main theme, broadly defined as Challenges and barriers to better care of older patients in ED.

The interview study did not require ethical approval (following discussion with the UK National Research Ethics Service) but it was registered with the National Institute for Health Research Coordinated System for gaining NHS Permission (reference 183694).

\section{Stakeholder Workshops - Intervention Development}

Based on the findings from two prioritisation exercises, two participatory workshops were conducted, involving a total of fifteen staff members with relevant, but diverse backgrounds including emergency medicine, pharmacy, microbiology, nursing and geriatrics. They were purposively selected and recruited according to their expertise, understanding of subject matter, and strategic role in change-making processes related to the care of older patients.

The first workshop, attended by nine participants, generated possible interventions informed by the interview. The putative interventions were categorised using the Behaviour Change Wheel framework [19]. The Behaviour Change Wheel synthesises 19 behaviour change frameworks and uses the COM-B model to identify areas for possible intervention: 'Capability', 'Opportunity', 'Motivation' and 'Behaviour'), recognising that behaviour is formed by interactions between all these components. In the second workshop six participants refined the interventions, aligning them with staff groups who might enact them. This process was assisted by the APEASE criteria (Affordability, Practicality, cost-Effectiveness, Acceptability, Side effects and Equity) [22].

Ethical approval for this phase was obtained from Loughborough University.

\section{Results}

\section{Interview study}

Twenty-one clinical staff members were interviewed, including doctors (three senior and five trainees) and nursing staff (three seniors, five juniors, five health care assistants). The interview findings were analysed and summarised using six COM-B model components. Factors contributing to the misdiagnosis of urinary tract infection related to psychological capability, reflective motivation and opportunities constrained by external factors. 
1. Psychological Capability - lack of knowledge on the role of urinary dipstick testing

Staff from both professions and at all levels had very little, if any, awareness of national or local guidelines regarding the diagnosis of UTI. All staff cited experiential or 'on the job' learning from other colleagues rather than referring to available guidelines.

HCA: 'I think...guidelines are there but there are guidelines for everything we do...we don't always read them'

There were conflicting views on the role of urinary dipstick testing. Some staff viewed the urine dip as a quick and simple means of diagnosing UTI; others were aware of limitations. Some felt that there may be over-use and over-reliance on urine testing. Senior doctors expressed their frustrations about the perceived lack of understanding of the role of urine testing amongst their colleagues.

HCA: 'nitrates and leucocytes...is positive'

Junior doctor: 'Nitrites... are specific to UTI'

Senior nurse: 'a positive test means a UTI'

Middle grade doctor: 'the urine dip is positive...doesn't necessarily mean UTI...could just be asymptomatic bacteriuria'

The majority of more seniors respondents felt that a positive urine dip result alone would not indicate a UTI, but in conjunction with symptoms could lend weight to the diagnosis. The presence of symptoms was thought to be the most important factor by respondents of all levels to trigger antibiotic treatment.

There were only a small number of respondents in our sample that were aware of asymptomatic bacteriuria. Concern was expressed by more senior members of staff that patients would be diagnosed and treated on the basis of a positive urine dip alone despite a lack of symptoms.

Several respondents felt that guidelines and education were needed regarding the interpretation of urine dips and that more input from senior clinicians should be sought in suspected UTI cases. Several of the doctors interviewed would welcome guidelines regarding the use and interpretation of urinary testing plus details of resources they could access. However, it was pointed out that the diversity (experience, specialism, culture) and high turnover of doctors working within ED could be another potential challenge which impacted upon 
education and training in ED. One interviewee advised a focus upon senior rather than junior doctors as a more effective mechanism for effecting change and improving practice.

2. Reflective Motivation - bias towards older people

Across all professions, older people were identified as being more likely to have their urine tested and be subsequently labelled as having a UTI.

\author{
HCA: 'I would say just about every elderly person that comes through the door there's a \\ possibility of UTI. When somebody's got a strong UTI you know they have. You can smell \\ it anyway.' \\ Senior doctor: 'virtually every older patient who comes in the department gets asked for a \\ urine sample...so a patient needs to wee anyway and you dip it, and it's a cheap test'
}

Several staff members described the complexities of assessing an older person with a range of problems.

3. Physical Opportunity - cues from automatic urine testing practice

Urine dipstick testing was described as forming part of several protocols including the initial assessment process, the sepsis bundle, the falls assessment and the confusion screen. The urinary testing was often conducted prior to assessment by a doctor or senior nurse.

Senior nurse: 'the Falls Pathway we use in ED suggests urine dip...as well as the sepsis proforma...literally everybody, so as soon as you pee, everybody gets a dip stick'

Urinary testing was often described as being an 'automatic' test for patients presenting in ED, particularly older people. Lack of symptoms of UTI was given as a reason not to test urine by all grades of staff, yet lack of symptoms did not prevent urine being dipped.

Staff nurse: 'It's just an automatic thing that we do'

HCA: 'I'd automatically do it'

Senior nurse: 'it gets the tick in the box'

HCA: 'I'm not bothered if it's negative... as long as I've tested it' 
Senior staff members admitted to fear that ED had become process driven and had moved away from patient centred care and outcomes.

Senior doctor: 'we're not tailoring care to the specific patient'

4. Physical Opportunity - time and resource constraints

Time pressures within the ED and need for efficiency were cited by some as a reason for early urine testing. The drive to diagnose or 'label' patients was perceived to have contributed to an over-reliance on testing at the expense of evidence-based medicine.

Middle grade doctor: 'we have a carpet bomb approach...to investigations in the assessment bay'

Senior doctor: 'because of the time pressures...everyone is trying to take short cuts'

Maintaining patient flow in the Emergency Department was often a priority; urine testing and quickly diagnosing UTI was described as a method of securing hospital admission.

Senior nurse: 'need to find a cause to admit somebody to hospital when we think they're not right to go home, we've only got so much time to make the decision...so that's what

I'm going to come up with'

Clinicians commented that further assessment and tests may be undertaken on the admission wards and thus if the positive urinary test was found to be an inadequate explanation for the patient's symptoms, the true diagnosis may then be sought.

5. Social Opportunity - social pressures from peer and patients

While some staff felt sufficiently empowered not to allow the social pressures to affect their clinical judgement, others felt that testing urine was their contribution to the diagnostic process and also that achieving a diagnosis (using a dip) helped address perceived pressures from patients and their relatives.

Middle grade doctor: urinary testing allows you 'to feel and look like you're actively doing something' 
One member of staff suggested that patients and their relatives perceive treatment with antibiotics better than not treating the patient at all, even if this is the wrong treatment based on an inaccurately interpreted or inappropriate test.

Doctors and nurses also commented on perceived pressures placed upon junior doctors by their senior colleagues: they described a fear of feeling humiliated or of being reprimanded for missing a diagnosis.

6. Social Opportunity - fear of the legal consequences of inaction

The fear of 'missing something', for example urosepsis, was cited by almost all grades and professions as a reason for urinary testing. Some doctors felt that a urine dip test might help mitigate possible consequences of a missed diagnosis; this sentiment was also expressed by some nurses.

\title{
Senior doctor: 'People are constantly afraid they're going to miss something and they don't want to miss anything so..... what they are doing is ticking the boxes'
}

Senior doctor: 'junior doctors are at risk of confirmation bias, and ignoring whatever else might be there... as they're desperate to pin something on the patient'

A senior doctor and nurse commented on wider pressures and the litigious culture. Comments were also made regarding the need to 'cover oneself' in the context of a perceived lack of organisational support. Such pressures were also thought to contribute to questionable clinical decisions.

\author{
Senior doctor: 'it is also a fear that if something goes wrong with the patient nobody's \\ going to support you... the system is wrong and driving perverse clinical behaviour' \\ Senior nurse: 'it's almost like there's a culture now of got to cover my backside before \\ we'll do anything'
}

Table 1 summarises the emerging themes identified. 
Table 1 Challenges and barriers to better care of UTI in older patients in ED

\begin{tabular}{|c|c|c|}
\hline COM-B & \multicolumn{2}{|l|}{ Descriptions } \\
\hline $\begin{array}{l}\text { Psychological } \\
\text { capability }\end{array}$ & Lack of knowledge & $\begin{array}{l}\text { ED staff often make prejudiced judgements based on inaccurate } \\
\text { assumptions about UTI presentation and treatment choices. }\end{array}$ \\
\hline $\begin{array}{l}\text { Reflective } \\
\text { Motivation }\end{array}$ & Bias towards older people & $\begin{array}{l}\text { Across all clinicians, older people were identified as being more } \\
\text { likely to have their urine tested and be subsequently labelled as } \\
\text { having a UTI. }\end{array}$ \\
\hline \multirow[t]{2}{*}{$\begin{array}{l}\text { Physical } \\
\text { opportunity }\end{array}$} & $\begin{array}{l}\text { Cues from automatic urine } \\
\text { dip stick testing practice }\end{array}$ & $\begin{array}{l}\text { The urinary dipstick testing was often conducted automatically } \\
\text { prior to assessment by a doctor or senior nurse. }\end{array}$ \\
\hline & $\begin{array}{l}\text { Time and resource } \\
\text { constraints }\end{array}$ & $\begin{array}{l}\text { Time and resource constraints were a reason for early urine } \\
\text { testing and misdiagnosis of UTI. The priority was often to } \\
\text { diagnose patients and maintain patient flow. }\end{array}$ \\
\hline \multirow[t]{2}{*}{$\begin{array}{l}\text { Social } \\
\text { opportunity }\end{array}$} & $\begin{array}{l}\text { Pressures from peers and } \\
\text { patients }\end{array}$ & $\begin{array}{l}\text { Patients/carers prefer any treatment including antibiotics than } \\
\text { no treatment and junior doctors had a fear of feeling humiliated } \\
\text { or of being reprimanded for missing a diagnosis by their senior } \\
\text { colleagues. }\end{array}$ \\
\hline & $\begin{array}{l}\text { Fear of the legal } \\
\text { consequences }\end{array}$ & $\begin{array}{l}\text { Staff are under pressure to avoid any missed diagnosis to 'cover } \\
\text { oneself' in an increasingly litigious culture. }\end{array}$ \\
\hline
\end{tabular}

Figure 1 shows the thematic networks map which displays the data gathered in the interviews and then expanded during group discussions.

Figure 1 Thematic Networks Map - about here 


\section{Intervention development}

The main result of the first workshop was a large volume of ideas to tackle two main challenges: lack of understanding of symptoms and diagnostics of UTI; automatic urine dip testing of older adults regardless of patients' symptoms and presentation. Intervention ideas generated during the workshop were later clustered in six groups, gathered around the kind of impact or influence they might elicit (Table 2).

Table 2 Outputs from the 'idea-generation' workshop

\begin{tabular}{|c|c|c|c|}
\hline $\begin{array}{l}\text { Barriers (affected } \\
\text { COM-B } \\
\text { components) }\end{array}$ & Intervention Functions* & Policy Categories* & $\begin{array}{l}\text { Examples of ideas generated by } \\
\text { the group of stakeholders }\end{array}$ \\
\hline $\begin{array}{l}\text { Lack of } \\
\text { knowledge } \\
\text { (Psychological } \\
\text { capability) }\end{array}$ & $\begin{array}{l}\text { Education } \\
\text { Training } \\
\text { Enablement }\end{array}$ & $\begin{array}{l}\text { Communications \& } \\
\text { marketing } \\
\text { Service provision }\end{array}$ & $\begin{array}{l}\text { Provide training to make sure all } \\
\text { staff are confident in their } \\
\text { knowledge of UTI so that they } \\
\text { can challenge current practice. } \\
\text { Individualised feedback letter on } \\
\text { random sub-sample, highlighting } \\
\text { consequences of poor outcomes } \\
\text { for older people as result of } \\
\text { antibiotics from dip. }\end{array}$ \\
\hline $\begin{array}{l}\text { Bias towards } \\
\text { older people } \\
\text { (Reflective } \\
\text { Motivation) }\end{array}$ & $\begin{array}{l}\text { Education } \\
\text { Persuasion } \\
\text { Coercion }\end{array}$ & $\begin{array}{l}\text { Communications \& } \\
\text { marketing } \\
\text { Guidelines } \\
\text { Regulation } \\
\text { Environmental and } \\
\text { social planning }\end{array}$ & $\begin{array}{l}\text { Make it trust policy not to dip } \\
\text { urine in } 65+\text { patients. } \\
\text { Change the "sepsis bundle" } \\
\text { sheet, which is systematically } \\
\text { used and has tick boxes. One of } \\
\text { these could state: Urine dip for } \\
<65 \text { only. }\end{array}$ \\
\hline
\end{tabular}




\begin{tabular}{|c|c|c|c|}
\hline $\begin{array}{l}\text { Cues from } \\
\text { automatic urine } \\
\text { testing practice } \\
\text { (Physical } \\
\text { opportunity) }\end{array}$ & $\begin{array}{l}\text { Training } \\
\text { Restriction } \\
\text { Environmental } \\
\text { restructuring } \\
\text { Enablement }\end{array}$ & $\begin{array}{l}\text { Communications \& } \\
\text { marketing } \\
\text { Guidelines } \\
\text { Regulation } \\
\text { Environmental and } \\
\text { social planning } \\
\text { Service provision }\end{array}$ & $\begin{array}{l}\text { Replace dip test with symptom } \\
\text { check list. } \\
\text { Develop a better "dipstick" - e.g. } \\
\text { a UTI heuristic that staff use } \\
\text { instead of the traditional } \\
\text { dipstick. } \\
\text { Monitor dip sticks like } \\
\text { controlled drugs two signatures } \\
\text { needed, making it difficult to } \\
\text { use. }\end{array}$ \\
\hline $\begin{array}{l}\text { Time and } \\
\text { resource } \\
\text { constraints } \\
\text { (Physical } \\
\text { opportunity) }\end{array}$ & Enablement & $\begin{array}{l}\text { Communications \& } \\
\text { marketing } \\
\text { Environmental and } \\
\text { social planning } \\
\text { Service provision }\end{array}$ & $\begin{array}{l}\text { Provide 'official channels' } \\
\text { (WhatsApp, phone, hotline, in } \\
\text { person, email etc.) to allow } \\
\text { direct access to UTI experts } \\
\text { within the ED. }\end{array}$ \\
\hline $\begin{array}{l}\text { Pressures from } \\
\text { peers and } \\
\text { patients (Social } \\
\text { opportunity) }\end{array}$ & $\begin{array}{l}\text { Restriction } \\
\text { Environmental } \\
\text { restructuring } \\
\text { Modelling } \\
\text { Enablement }\end{array}$ & $\begin{array}{l}\text { Communications \& } \\
\text { marketing } \\
\text { Regulation } \\
\text { Environmental and } \\
\text { social planning } \\
\text { Service provision }\end{array}$ & $\begin{array}{l}\text { Challenge staff to count the } \\
\text { number of dips they do each day } \\
\text { and to reduce the number they } \\
\text { do. } \\
\text { Feedback loop to individual } \\
\text { doctors about outcome of } \\
\text { patients to reinforce evidence } \\
\text { and 'expose' inefficiency of dip } \\
\text { testing. }\end{array}$ \\
\hline $\begin{array}{l}\text { Fear of the legal } \\
\text { consequences }\end{array}$ & --- & --- & $\begin{array}{l}\text { No ideas were developed } \\
\text { regarding this issue due to the }\end{array}$ \\
\hline
\end{tabular}




$\begin{aligned} & \text { (Social } \\ & \text { opportunity) }\end{aligned}$
* The Behaviour Change Wheel framework establishes nine intervention functions and seven policy
categories. Intervention functions are "broad categories of means by which an intervention can change
behaviour"; policy categories are ways to "support the delivery of intervention functions".
Specific intervention functions can be associated with the components of the COM-B model implicated in the
identified undesirable behaviours. Policy categories are then matched to the chosen intervention functions to
allow appropriate idea-generation and solution-development. This process seeks to amplify the effectiveness
of the proposed interventions by aligning behavioural causation with mechanisms capable of changing the
specific manifestations of 'inappropriate' or 'undesirable' behaviour.

The analysis and prioritisation of the potential groups of ideas led to the identification of the following two ideas that achieved higher scores when assessed using the APEASE criteria.

1. Devising mechanisms to control the use of dip stick urine tests in the emergency department;

2. Providing individualised feedback to staff regarding the outcomes of patients diagnosed and treated for UTI

The first idea works from a regulatory/restrictive vantage point, whereby limiting access to dips is intended to reduce the impact of test results in the determination of treatment courses. The second idea is supported by the belief that informing staff about the consequences of their treatment decisions will facilitate reflective practice and provoke behaviour changes. The first idea is more of "quick fix" to bring down the use of dips that artificially alters routine practice in a somewhat abrupt manner; the latter is more of a gradual process that would nonetheless have some immediate impact in raising awareness and surfacing clinical decision-making choices, potentially building on social pressure strategies. A fuller 'framework' for improvement that could potentially be tested in other settings is included in Appendix 1.

\section{Discussion}

This study provides insights into the psychological and behaviour factors contributing to the misdiagnosis of UTI in older people in the emergency department setting. Common themes included a lack of knowledge on the 
role of urine dipstick testing, bias towards older people, automatic testing practice, pressures from time and resource constraints, pressures from patients and peers, and legal pressures.

This research was performed in a large, busy ED department but further research is needed to investigate the generalisability of our findings. The sampling strategy ensured a variety of clinicians at different levels of seniority/experience were represented. Sampling and analysis were concurrent, and indicated that no new themes were emerging [23].

As with other studies [5-8], this study also identified the complexities involved in assessing older people. Nonspecific presentations, difficulties with communication due to cognitive impairment or language barriers, and lack of relevant information can all make reaching a timely and accurate diagnosis challenging [7, 24, 6, 14]. Older patients are often tested routinely in the absence of symptoms and without prior clinical assessment; 'watchful waiting' and accepting a degree of diagnostic uncertainty are poorly tolerated, particularly amongst the more junior doctors $[25,26]$. Uncertainty leads to overprescribing antibiotics - a trend also seen in antibiotic prescribing for lower respiratory tract infections [27]. There was evidence of limiting thinking and narrow assessments of older people, for example failing to consider causes of smelly urine apart from UTI (incontinence, food (asparagus, garlic) and medications (e.g. vitamin B).

However, training alone is not sufficient to address this issue which was caused by complex interactions of multiple factors. Approaches incorporating these factors can potentially improve patient safety, efficiency, costs from unnecessary testing and staff satisfaction (Appendix 1). Systemic approaches such as these may facilitate a more constructive approach to improvement which moves away from blaming individuals to recognising the interconnected complexity of influencing factors.

There are messages here for teams interested in improving the management of UTI, not least the importance of recognising the complexity of the issue, especially in the ED setting - and the need to develop a broad framework of interventions. A single intervention implemented in isolation is unlikely to achieve impact. Future work should involve implementing and evaluating approaches identified in this study, adapted to the local context.

\section{Conclusion}

Diagnosing Urinary Tract Infection in older people in urgent care settings is a complex issue. Interventions to improve diagnostic accuracy will need to take a multifaceted approach, focusing upon staff, resources and 
environment. This work outlines a framework which could be used by services to improve their approach to the common and serious issue of misdiagnosis of Urinary Tract Infection in older people. 
Appendix 1 Possible roadmap for improving UTI management in Emergency Departments

\begin{tabular}{|c|c|c|}
\hline Timeframe of Focus & Stages & Questions to consider \\
\hline \multirow[t]{2}{*}{ Short-term } & Raise Awareness & $\begin{array}{l}\text { Are people aware that UTI misdiagnosis is an issue that } \\
\text { needs attention? }\end{array}$ \\
\hline & $\begin{array}{l}\text { Understand Beliefs } \\
\text { about Severity and } \\
\text { Consequences }\end{array}$ & $\begin{array}{l}\text { Do people believe that not addressing the UTI } \\
\text { misdiagnosis issue may have negative consequences to } \\
\text { patients and the public (value-based arguments), as well } \\
\text { as budgetary costs for the system (health economics } \\
\text { arguments)? }\end{array}$ \\
\hline \multirow[t]{4}{*}{ Mid-term } & $\begin{array}{l}\text { Map Knowledge and } \\
\text { Skills }\end{array}$ & $\begin{array}{l}\text { Do people know what they need to know about UTI } \\
\text { diagnosis/treatment, and know how to do what they need } \\
\text { to do? }\end{array}$ \\
\hline & $\begin{array}{l}\text { Nurture Beliefs about } \\
\text { Positive Impact }\end{array}$ & $\begin{array}{l}\text { Do people believe that their actions and behaviours can } \\
\text { help changing the outcomes? }\end{array}$ \\
\hline & $\begin{array}{l}\text { Identify Social and } \\
\text { Environmental Support }\end{array}$ & $\begin{array}{l}\text { Are the social, organisational, and environmental } \\
\text { conditions in place to support the necessary changes? }\end{array}$ \\
\hline & $\begin{array}{l}\text { Devise Action Plans } \\
\text { and Strategies }\end{array}$ & $\begin{array}{l}\text { Is there a clear strategy to tackle the UTI misdiagnosis } \\
\text { issues with specific actions assigned to each group of } \\
\text { professionals/ stakeholders? }\end{array}$ \\
\hline \multirow[t]{2}{*}{ Long-term } & $\begin{array}{l}\text { Implement Continued } \\
\text { Action }\end{array}$ & $\begin{array}{l}\text { Are people taking the right actions according to the } \\
\text { agreed-upon plan? }\end{array}$ \\
\hline & $\begin{array}{l}\text { Promote Feedback and } \\
\text { Learning Cycles }\end{array}$ & $\begin{array}{l}\text { Are people getting continuous feedback on the outcomes } \\
\text { and impact resulting from the interventions and receiving } \\
\text { additional support where needed? }\end{array}$ \\
\hline
\end{tabular}




\section{References}

1. National Institute for Health and Care Excellence. Urinary tract infections in adults. London2015.

2. SIGN. Management of suspected bacterial urinary tract infection in adults. A national clinical guideline. 2006.

3. Scottish Intercollegiate Guidelines Network. Management of suspected bacterial urinary tract infection in adults. 2012.

4. Nicolle LE, Gupta K, Bradley SF, Colgan R, DeMuri GP, Drekonja D et al. Clinical Practice Guideline for the Management of Asymptomatic Bacteriuria: 2019 Update by the Infectious Diseases Society of Americaa. 2019. doi:10.1093/cid/ciy1121.

5. Vanpee D, Swine C, Vandenbossche P, Gillet J. Epidemiological profile of geriatric patients admitted to the emergency department of a university hospital localized in a rural area. European Journal of Emergency Medicine. 2001;8(4):301-4.

6. Nemec $M$, Koller $M$, Nickel $C$. Patients presenting to the emergency department with non-specific complaints: the Basel Non-specific Complaints (BANC) study. Acad Emerg Med. 2010 17(3):284-92. doi:10.1111/j.1553-2712.2009.00658.x.

7. Limpawattana $\mathrm{P}$, Phungoen $\mathrm{P}$, Mitsungnern $\mathrm{T}$, Laosuangkoon $\mathrm{W}$, Tansangworn $\mathrm{N}$. Atypical presentations of older adults at the emergency department and associated factors. Archives of Gerontology \& Geriatrics. 2016;62:97-102.

8. Eriksson I, Gustafson Y, Fagerstrom L, Olofsson B. Urinary tract infection in very old women is associated with delirium. International Psychogeriatrics. 2011;23(3):496-502. 9. Manepalli J, Grossberg GT, Mueller C. Prevalence of delirium and urinary tract infection in a psychogeriatric unit. Journal of Geriatric Psychiatry \& Neurology. $1990 ; 3(4): 198-202$.

10. Wojszel ZB, Toczyńska-Silkiewicz M. Urinary tract infections in a geriatric sub-acute ward-health correlates and atypical presentations. European Geriatric Medicine. 2018;9(5):659-67. doi:10.1007/s41999-018-0099-2.

11. Nicolle LE, Bradley S, Colgan R, Rice JC, Schaeffer A, Hooton TM. Infectious diseases society of America guidelines for the diagnosis and treatment of asymptomatic bacteriuria in adults. Clinical Infectious Diseases. 2005;40(5):643-54. doi: $10.1086 / 427507$.

12. Mody $L$, Juthani-Mehta $M$. Urinary tract infections in older women: a clinical review. JAMA. 2014;311(8):844-54. doi:10.1001/jama.2014.303.

13. Ninan S, Walton C, Barlow S. Investigation of suspected urinary tract infection in older people. . Britsh Medical Journal. 2014.

14. Finucane TE. "Urinary Tract Infection"-Requiem for a Heavyweight. Journal of the American Geriatrics Society. 2017;65(8):1650-5. doi:10.1111/jgs.14907.

15. O'Kelly K, Regen E, Phelps K, Kondova D, Conroy S. Urinary tract infection - a qualitative study exploring the human factors contributing to misdiagnosis. European Geriatric Medicine. 2016;7(1):s1-282.

16. Genao L, Buhr GT. Urinary Tract Infections in Older Adults Residing in Long-Term Care Facilities. Ann Longterm Care. 2012;20(4):33-8.

17. Nace DA, Drinka PJ, Crnich CJ. Clinical uncertainties in the approach to long term care residents with possible urinary tract infection. J Am Med Dir Assoc.

2014;15(2):133-9. doi:10.1016/j.jamda.2013.11.009.

18. Beveridge LA, Davey PG, Phillips G, McMurdo MET. Optimal management of urinary tract infections in older people. Clinical Interventions in Aging. 2011;6:173-80.

doi: $10.2147 /$ CIA.S13423.

19. Michie S, van Stralen M, West R. The behaviour change wheel: A new method for characterising and designing behaviour change interventions. Implementation Science. $2011 ; 6(1): 42$.

20. Gladman JRF, Conroy SP, Ranhoff AH, Gordon AL. New horizons in the implementation and research of comprehensive geriatric assessment: knowing, doing and the 'know-do' gap. Age and Ageing. 2016;45(2):194-200.

doi: 10.1093/ageing/afw012. 
21. Ritchie J, Spencer L. Analyzing qualitative data. In: Bryman A, Burgess R, editors. Qualitative data analysis for applied policy research. London: Routledge; 1994. p. 17394.

22. Michie S, Atkins $L$, West R. The APEASE criteria for designing and evaluating interventions. The Behaviour Change Wheel: A Guide to Designing Interventions. London: Silverback Publishing; 2014.

23. Fusch $P$, Ness L. Are We There Yet? Data Saturation in Qualitative Research2015. 24. Misch F, Messmer AS, Nickel CH, Gujan M, Graber A, Blume K et al. Impact of Observation on Disposition of Elderly Patients Presenting to Emergency Departments with Non-Specific Complaints. PLoS ONE. 2014;9(5):e98097.

doi:10.1371/journal.pone.0098097.

25. Schmiemann G, Kniehl E, Gebhardt K, Matejczyk MM, Hummers-Pradier E. The diagnosis of urinary tract infection: a systematic review. Dtsch Arztebl Int. 2010;107(21):361-7. doi:10.3238/arztebl.2010.0361.

26. Logan RL, Scott PJ. Uncertainty in clinical practice: implications for quality and costs of health care. The Lancet. 1996;347(9001):595-8.

doi:http://dx.doi.org/10.1016/S0140-6736(96)91284-2.

27. Little P, Stuart B, Moore M, Coenen S, Butler CC, Godycki-Cwirko M et al. Amoxicillin for acute lower-respiratory-tract infection in primary care when pneumonia is not suspected: a 12-country, randomised, placebo-controlled trial. The Lancet Infectious Diseases. 2013;13(2):123-9. doi: http://dx.doi.org/10.1016/S1473-3099(12)70300-6. 
Figure 1 Thematic Networks Map - complex interactions between contributing factors

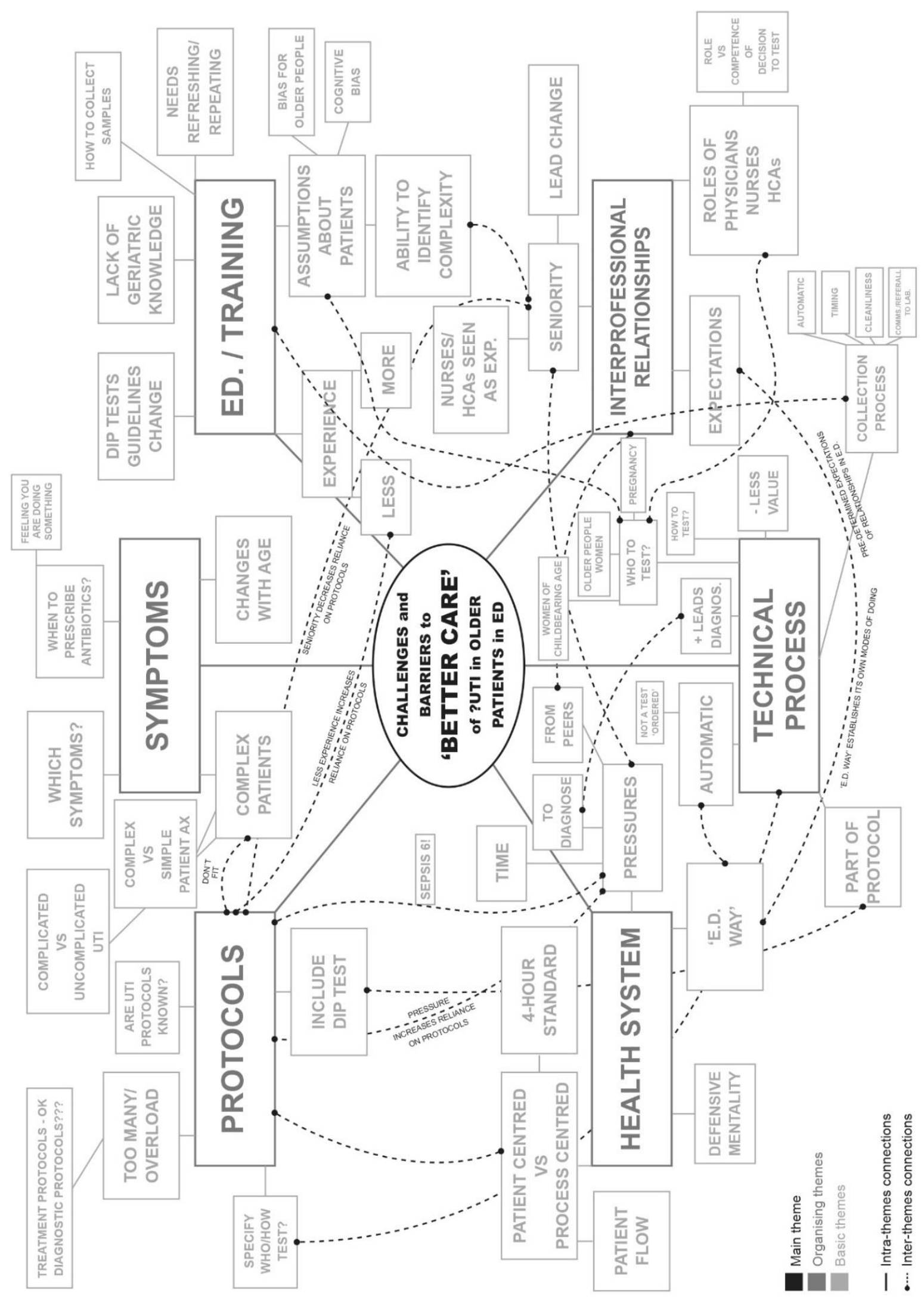

